\title{
Certain biological properties of multipotent mesenchymal stromal cells from bone marrow and adipose tissue of $\mathrm{FVB} / \mathrm{N}$ mice
}

\author{
Rodnichenko A. E. \\ State Institute of Genetic and Regenerative Medicine of the National Academy of Medical Sciences of Ukraine, Kyiv, Ukraine \\ e-mail: arodnichenko@ukr.net
}

\section{ABSTRACT}

Multipotent mesenchymal stromal cells (MMSCs) are used for cell therapy of lesions of various genesis. The most widely used MMSCs are from two tissue sources: bone marrow and adipose tissue.

The PURPOSE of the work was to conduct a comparative assessment of the biological properties of murine bone marrow-derived and adipose tissue-derived MMSCs.

METHODS. The culture of MMSCs was obtained from the bone marrow and adipose tissue of 6 months-old male FVB/N mice according to standard protocols. We performed phenotyping, directed osteogenic and adipogenic differentiation, analysis of immunomodulatory properties in vitro of obtained cell cultures.

RESULTS. The cultured MMSCs from bone marrow and adipose tissue express the typical stromal markers (CD44, CD73, CD90 and Sca-1). A distinctive feature of bone marrow cells cultures of the $2^{\text {nd }}$ passage was the high level of the hematopoietic markers CD45 and CD117 expression. MMSCs from both tissue sources are capable of differentiation in the osteogenic and adipogenic directions. At the same time, there were differences in the differentiation in the osteogenic direction - adipose tissue-derived MMSCs had a lower osteogenic potential. MMSCs exhibit inhibitory effect on mitogen-induced proliferation of splenocytes in vitro, expression of which does not depend on tissue origin of the MMSCs with significant inhibition of mitogen-induced proliferation of splenocytes at addition of high doses of MMSCs.

CONCLUSIONS. MMSCS of bone marrow and adipose tissue express a similar level of surface markers that are characteristic of cells with multipotent properties. They are capable to differentiating in osteo- and adipogenic direction with differences in the degree of mineralization of the extracellular matrix and exhibit immunomodulatory effects in vitro, regardless of tissue origin.

KEYWORDS: multipotent mesenchymal stromal cells; bone marrow; adipose tissue; directed cell differentiation; immunomodulation

Multipotent mesenchymal stromal cells (MMSCs) are primitive precursors that give rise to various types of connective tissue. Their common feature is their generation from mesenchyme during embryogenesis. To date, they have been found in many organs and tissues of the body, such as bone marrow [1], adipose tissue [2], hair follicle [3], placenta [4], umbilical cord blood [5, 6], synovial membrane [7], periosteum [8], skeletal muscle [9], skin [10], peripheral blood [11].

Due to its availability, ease of cultivation, high proliferative potential, the ability to differentiate into tissue of mesenchymal and nonmesenchymal origin, trophic effects on damaged organs and tissues, MMSCs are a promising biomaterial in regenerative medicine. Thus, their effectiveness in the treatment of many diseases is shown in the experiment and the clinic: chronic non-healing wounds, myocardial infarction, bone fractures, diabetes, critical limb ischemia, etc. $[12,13]$. The possibility of using MMSCs for the treatment of autoimmune diseases, reducing the risk of graft versus host disease (GVHD) and increasing the survival of transplanted material due to their immunomodulatory properties is being explored [5, 14-17].

Nowadays, the most widely used are MMSCs from two sources: bone marrow and adipose tissue. Since the identification of bone marrow stem cells [18], they have become standard in tissue engineering and regenerative medicine. As for adipose tissue, Rodbell [19] described the 
isolation of rat mature adipocytes and progenitor cells for the first time. Subsequently, the procedure for the obtaining of adipose tissue cells was modified [20, 21].

Currently, both common and distinctive features of these types of cells have been identified. Thus, bone marrow-derived MMSCs (BM-MMSCs) and adipose tissue-derived MMSCs (AT-MMSCs) express a similar combination of surface antigens, growing as an adhesive cell population in the minimal nutrient media and capable of multilineage differentiation $[22,23]$. At the same time, these cells have certain differences in the potential for proliferation and differentiation. There is evidence that, unlike MMSCs from bone marrow, the MMSCs from adipose tissue have a higher proliferative potential. The doubling time in the logarithmic phase of growth is from 40 to 120 hours (depending on the age of the donor type and localization of adipose tissue, culture conditions) [24, 25]. Adipose tissue-derived MMSCs maintain the telomere length for longterm culture, while it is not clear whether telomerase activity remains at a constant level or decreases with passages [26]. However, there is evidence that there is no telomerase expression of adipose tissue-derived MMSCs [27]

Bone marrow biopsy is a painful procedure, in addition, the yield of MMSCs is low - they represent a very small fraction (0.001$0.01 \%$ ) [28]. For comparison, an average of $0.5-2.0 \cdot 10^{6}$ cells of stromal vascular fraction can be isolated from $1 \mathrm{~g}$ of adipose tissue, which yields $1-10 \%$ of stem cells [29-30]. The high content of MMSCs in adipose tissue eliminates the need for long-term cultivation in vitro, which reduces the risk of chromosomal abnormalities. These properties make adipose tissue MMSCs an attractive tool for clinical application. [31-33].

Therefore, a special interest is the comparison of the biological properties of MMSCs from various sources. The purpose of this work was to conduct a comparative analysis of surface markers expression, the ability to osteogenic and adipogenic differentiation, immunomodulatory properties of murine bone marrow-derived and adipose tissue-derived MMSCs.

\section{MATERIALS AND METHODS}

The cells were obtained from the bone marrow and adipose tissue of 6 months-old male FVB/N (genotype H-2q) mice. The animals were obtained from the vivarium of State Institute of Genetic and Regenerative Medicine NAMS Ukraine. For euthanasia of mice, an overdose of diethyl ether was used. All procedures with experimental animals were carried out in compliance with the national and international laws as well as principles of bioethics [34]. Isolation, cultivation and directed differentiation of MMSCs were performed according to standard protocols [35]. We used cells of the $2^{\text {nd }}$ passage, the MMSCs-like properties of which were confirmed by the appropriate phenotype, osteogenic and adipogenic differentiation ability [36].

Single cell suspension of bone marrow was obtained by flushing the femurs of the mice with the RPMI-1640 medium, followed by transferring the suspension to culture flask with a surface area of $25 \mathrm{~cm}^{2}$. Cultivations were carried out in a nutrient medium RPMI-1640 containing $10 \%$ FBS, $2 \mathrm{mM}$ L-glutamine, $100 \mathrm{IU} / \mathrm{ml}$ penicillin, $100 \mu \mathrm{g} / \mathrm{ml}$ streptomycin (all Sigma, USA).

Adipose tissue-derived MMSCs were obtained by enzyme digestion of minced murine adipose tissue in $0.1 \%$ solution of collagenase $1 \mathrm{~A}$ for 2 hours at $37^{\circ} \mathrm{C}$. After inactivation of collagenase with DMEM medium with $10 \%$ fetal bovine serum (FBS), cell suspension was centrifuged at $300 x g$ for 10 min.

The supernatant was removed and cell pellets were plated onto a tissue culture plate in DMEM/F12 medium supplemented with $10 \% \mathrm{FBS}, 2 \mathrm{mM}$ L-glutamine, $100 \mathrm{lU} / \mathrm{ml}$ penicillin, $100 \mu \mathrm{g} / \mathrm{ml}$ streptomycin (all - Sigma, USA) and incubated at $37{ }^{\circ} \mathrm{C}$. Cells were grown in $5 \% \mathrm{CO}_{2}$ at $37^{\circ} \mathrm{C}$ and passaged by trypsinization when they reached $>80 \%$ confluence.

The phenotyping of cells was performed using the monoclonal antibodies specific for membrane antigens such as CD44, CD45, CD73,
CD90, CD117 and Sca-1 conjugated with fluorochromes (BD Biosciences, USA) in a working concentration of $0.5 \mu \mathrm{g} / \mathrm{ml}$. Cell samples without antibodies were used as an unstained control. The fluorescence level in the sample with monoclonal antibodies was evaluated with each antibody alone (single staining sample). Measurements were performed with BD FACSAria cell sorter (Becton Dickinson, USA) using the BD FACSDiva 6.1 software. Histogram merging was performed using Cyflogic v.1.2.1 software.

For directed osteogenic differentiation the cells were cultured in osteoinductive medium containing DMEM-LG (1 g/l glucose) supplemented with $10 \%$ of FBS, $0.05 \mathrm{mM}$ L-ascorbic acid 2-phosphate, $100 \mathrm{nM}$ dexamethasone, and $10 \mathrm{mM} \beta$-glycerophosphate (all - Sigma, USA). Osteogenic medium was replaced every 3 days. After 21 days, the cell monolayer was fixed with $10 \%$ cold paraformaldehyde and stained with $2 \%$ solution of Alizarin Red S (Sigma, USA) to detect mineralization of extracellular matrix [37]. The semi-quantitative analysis of the extent of mineralization of Alizarin Red S stained cultures was performed by colorimetric assay [38]. Dye that bind calcified matrix was extracted with acetic acid, the $\mathrm{pH}$ was adjusted to 4.1 by ammonium hydroxide. An optical density was measured using a microplate spectrophotometer LabSystems Multiskan EX (Thermo Scientific, USA) at a wavelength of $405 \mathrm{~nm}$.

For directed adipogenic differentiation, the cells were cultured in adipogenic medium containing DMEM-HG (4.5 g/l glucose) supplemented with $10 \% \mathrm{FBS}, 1 \mu \mathrm{M}$ dexamethasone, $200 \mu \mathrm{M}$ indomethacin, 500 $\mu \mathrm{M}$ isobutylmethylxanthine, and $5 \mu \mathrm{g} / \mathrm{ml}$ insulin (all - Sigma, USA). Adipogenic medium was replaced every 3 days. After 14 days in culture, the cells were fixed in cold $10 \%$ paraformaldehyde and stained with Oil Red 0 solution (Sigma, USA) to detect lipid inclusions [39]. The number of cells with lipid vacuoles was counted in 10 randomly visual fields.

In order to determine the immunomodulatory properties of bone marrow and adipose tissue-derived MMSCs in vitro, a co-culture of MMSCs with syngeneic splenocytes stimulated by phytohaemagglutinin (PHA) was performed. MMSCs at concentrations of $1.5 \cdot 10^{4}, 3.0 \cdot 10^{4}$, and $6.0 \cdot 10^{4}$ cells were added into wells of a 96 -well plate in a complete nutrient medium and incubated for two hours for cell adhesion. Two hours later, $10^{6}$ splenocytes per well and $0.01 \mathrm{mg} / \mathrm{ml}$ PHA were added. The proliferative activity of splenocytes was evaluated after $72 \mathrm{~h}$ of cultivation [40]. Two hours before the end of the incubation, $0.01 \mathrm{ml}$ of $0.5 \%$ solution of 3-(4,5-dimethylthiazole)-2,5-diphenyltetrazole bromide (Sigma, USA) was added to each well. After two hours of incubation at $37^{\circ} \mathrm{C}$, the formed formazan crystals were dissolved in $0.15 \mathrm{ml}$ of a $0.04 \mathrm{M}$ solution of $\mathrm{HCl}$ in isopropyl alcohol and the optical supernatant density was measured on a microplate spectrophotometer LabSystems Multiskan EX (Thermo Scientific, USA) at a wavelength $492 \mathrm{~nm}$. The results were presented as optical density and proliferation index (PI) in arbitrary units (a. u.):

$\mathrm{PI}=$ optical density of supernatant of mitogen-activated cultures of splenocytes + MMSCs / optical density of supernatant from cultures of splenocytes without MMSCs.

Control PI = optical density of supernatant of mitogen-activated cultures of splenocytes / optical density of supernatant of cultures of splenocytes without mitogen.

Statistical analysis was performed using the parametric statistics (Student's t-test) [41]. A difference between rates or values was considered statistically significant at the $95 \%$ confidence level $(p<0.05)$.

\section{RESULTS AND DISCUSSION}

\section{PHENOTYPIC CHARACTERISTICS OF BONE MARROW-DERIVED} AND ADIPOSE TISSUE-DERIVED MIMSCS.

The International Society for Cellular Therapy has proposed minimal criteria for defining multipotent mesenchymal stromal cells that involves expression of cell surface markers such as CD73 (ecto-5'-nucleotidase, SH3 or SH4), CD90 (Thy-1), CD105 (SH2 or endoglin). It should be noted that none of these molecules is strictly specific to MMSCs. Therefore, for the identification of MMSCs, it is necessary to show the absence 


\begin{tabular}{|c|c|c|c|c|c|c|}
\hline SOURCE OF MMSCS & CD44, \% & Sca-1, \% & CD73, \% & CD90, \% & CD45, \% & CD117, \% \\
\hline BM-MMSCS & $97.8 \pm 0.7$ & $87.7 \pm 7.5$ & $10.9 \pm 0.4$ & $93.6 \pm 1.4$ & $60.9 \pm 18.4$ & $95.5 \pm 0.8$ \\
\hline AT-MMSCS & $93.9 \pm 0.7$ & $88.2 \pm 10.5$ & $15.0 \pm 7.9$ & $98.9 \pm 0.2$ & $1.7 \pm 1.2$ & $4.6 \pm 0.1$ \\
\hline
\end{tabular}

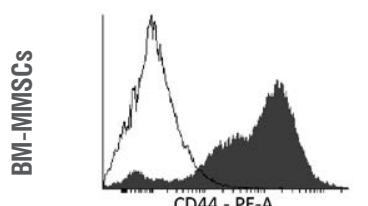

CD 44 - PE-A
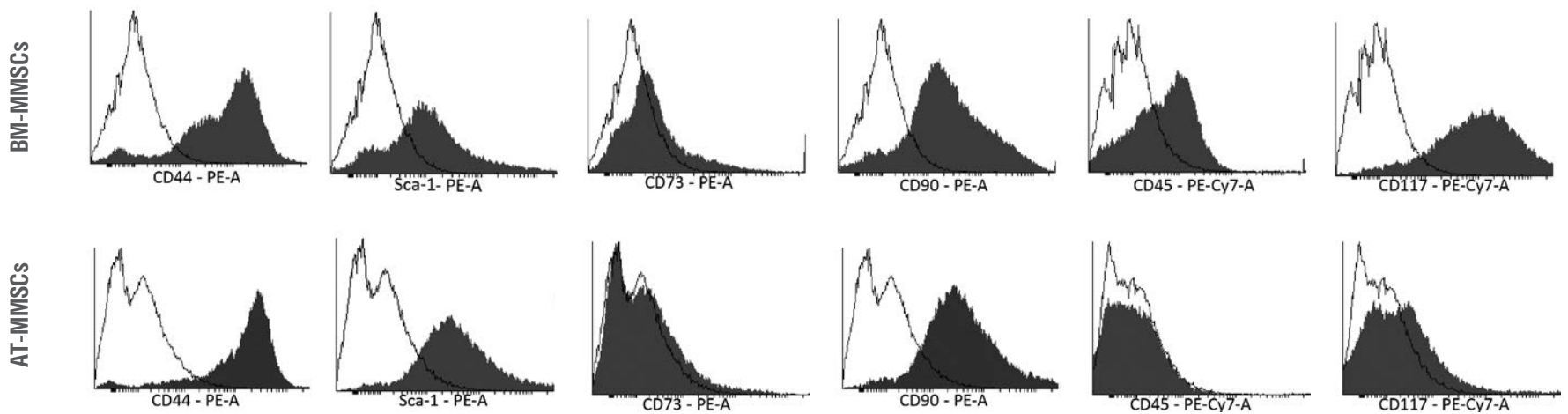

Fig. 1. FACS histograms of expression of surface markers CD44, Sca-1, CD73, CD90, CD45, CD117 in cultures of murine bone marrow-derived and adipose tissue-derived MMSCs, clear histogram - control samples without antibodies, dark - fluorescence level in the samples with monoclonal antibodies.

of hematopoietic cells: markers of monocytes and macrophages (CD11b or CD14), markers of the early hematopoietic cells and endothelial progenitors (CD34), pan-leukocyte marker (CD45), B-cell marker (CD19 or CD79a), and HLA-DR [36]. However, each research group uses its own set of antigens, which it considers most specific, or more appropriate and convenient for the intended purpose.

In our studies, we performed a comparative analysis of the expression of such surface markers: CD44 (Pgp1 - glycoprotein-1, that is persistently expressed by undifferentiated MMSCs), CD45 (leukocyte common antigen), CD73 (ecto-5'-nucleotidase), CD90 (thymocyte differentiation antigen 1, the expression decreases at the beginning of osteogenic differentiation), CD117 (c-kit, stem cell growth factor receptor), and Sca-1 (stem cell antigen) in the culture of stromal cells from bone marrow and adipose tissue.

Phenotypic analysis revealed a similar expression profile of surface markers that are typical for stromal cells with multipotent properties. Thus, the expression of CD44, CD73, Sca- 1 and CD90 antigens was detected on the cells of the $2^{\text {nd }}$ passage (see Table 1 and Fig. 1). It should be noted that standard methods do not allow to obtain a pure culture of murine bone marrow MMSCs. The culture of bone marrow cells in mice is heterogeneous as a result of the long-term survival of hematopoietic cells. Thus, cells with fibroblast-like morphology, large spread cells and small rounded cells were observed. Unlike the adipose tissue-derived MMSCs, the expression of hematopoietic markers CD45 and CD117 remained on bone marrow-derived MMSCs. Cultures of AT-MMSCs, in comparison with BM-MMSCs, are characterized by a morphologically homogeneous of cells and a higher rate of proliferation. AT-MMSCs were easily passaged in the ratio of 1:3 and 1:5. The time of reaching the confluence was 5-7 and 7-10 days, respectively. The cultures of bone marrow-derived cells were passaged in a ratio of $1: 2$ or 1:3, and the time of growth to confluence was 7-10 or 12-14 days, respectively. Consequently, our studies confirmed the literature data regarding such expression of surface antigens and the differences in potency to proliferation [22-25].

\section{FEATURES OF DIRECTED DIFFERENTIATION OF MURINE BONE} MARROW-DERIVED AND ADIPOSE TISSUE-DERIVED MIMSCS.

One of the main characteristics of MMSCs is the ability to differentiate into different types of connective tissue cells. To find out the differences in the biological properties of MMSCs, we determined the potential of these cells for directed differentiation in two orthodox directions: osteogenic and adipogenic.
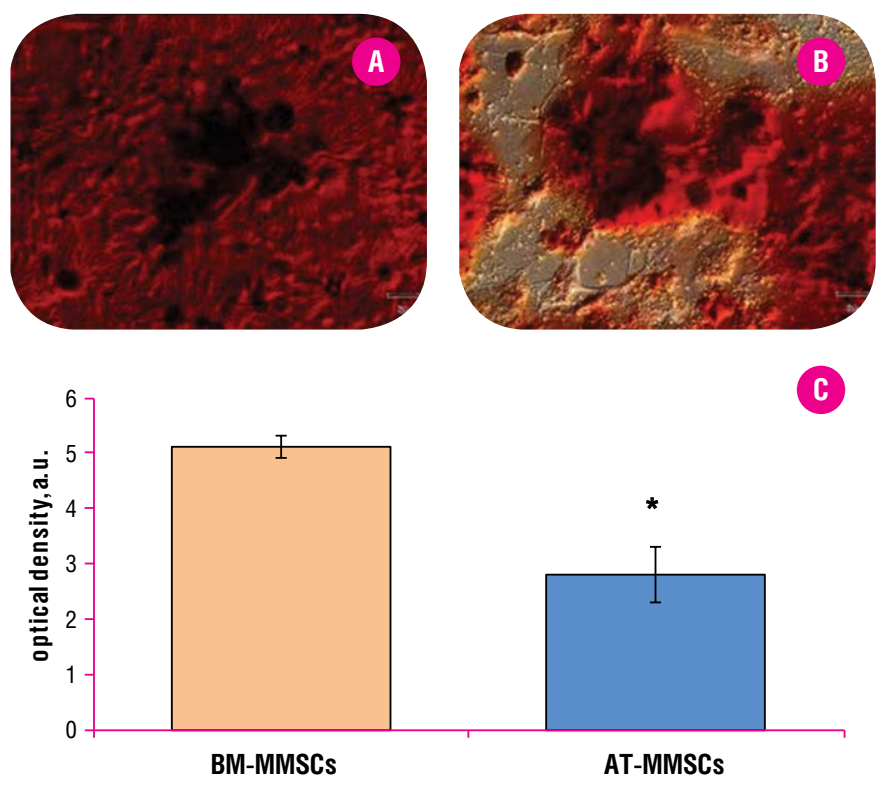



Fig. 2. Microphotographs of murine BM-MIMSCs (A) and AT-MIMSCs (B) cultures, differentiated in osteogenic direction, phase contrast, $x 400$. C - semi-quantitative analysis of the mineralization degree of BM-MMSCs and AT-MMSCs cultures (colorimetric method).

Note: ${ }^{*}-p<0.05$ compared to BM-MMSCs.

The first signs of the influence of an osteoinductive medium on MMSCs cultures appeared on the $7^{\text {th }}$ day of cultivation regardless of tissue origin. In analysis of the differentiation of cells in osteogenic direction, the MMSCs acquired a phenotype of bone tissue: they formed cellular aggregates and synthesized a dense extracellular matrix with subsequent calcification. It should be noted, that the mineralization of the extracellular matrix was more pronounced in the nodes of calcification, as well as spread throughout the area of culture. It was found, that the intensity of mineralization of bone marrow-derived MMSCs cultures was higher than that of adipose tissue-derived MMSCs: $5.1 \pm 0.2 \mathrm{a}$. u. and $2.8 \pm 0.5 \mathrm{a}$. u. optical density, respectively (Fig. 2). Perhaps this is due to the number of cells expressing osteoblast-specific transcription factors Runx2 (runt- 

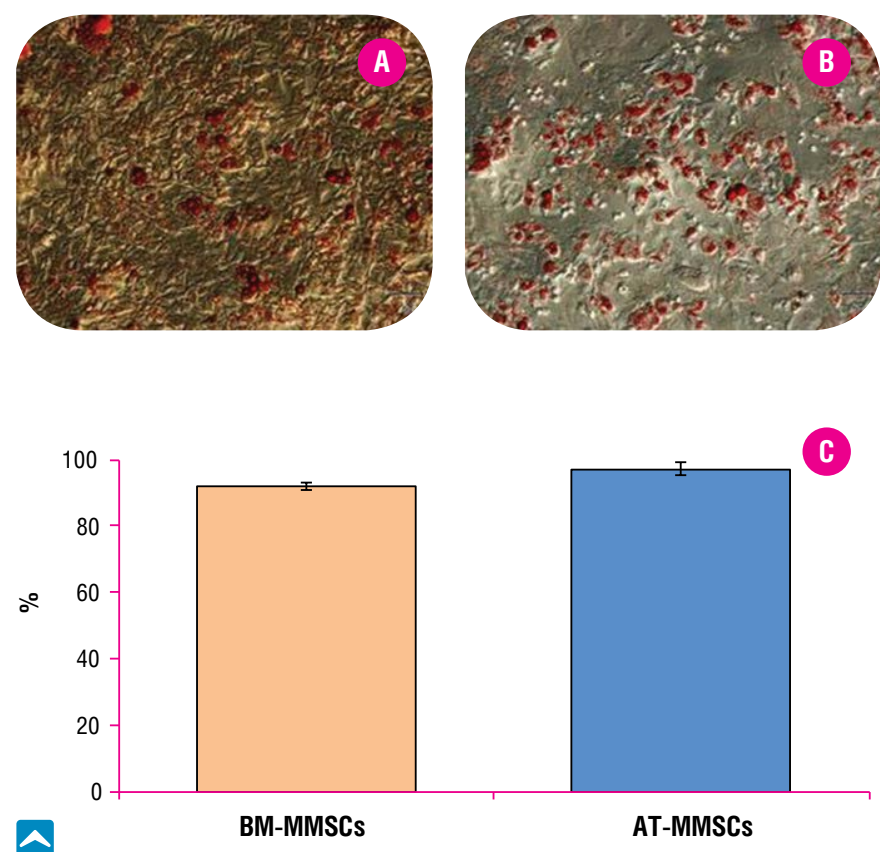

Fig. 3. Microphotographs of murine BM-MMSCs (A) and AT-MMSCs (B) cultures, differentiated in adipogenic direction, phase contrast, x200. C - relative number of BM-MMSCs and AT-MMSCs containing lipid vacuoles.

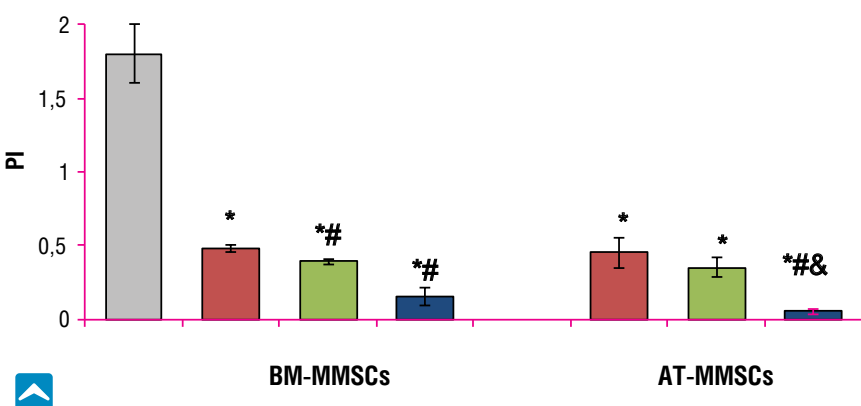

Fig. 4. Immunomodulatory effect of BM-MMSCs and AT-MMSCs on mitogen-induced proliferation index (PI) of mouse splenocytes. Notes: ${ }^{*}-p<0.05$ compared to control group; $\#-p<0.05$ compared o splenocytes co-cultured with $1.5 \cdot 10^{4}$ MMSCs; \& $-p<0.05$ compared to splenocytes co-cultured with 3.104 MMSCs. related transcription factor 2) and DIx5 (distal-less homeobox 5) [42]. It should be noted that we conducted research on mature male mice. There are studies showing that $17-\beta$-estradiol stimulates the expression of osteogenesis-related gene Cbfa1 and osteocalcin, increases the activity of alkaline phosphatase, the synthesis of extracellular matrix and its mineralization [43]. We can assume that significant changes in the degree of mineralization of the extracellular matrix, depending on the gender characteristics, are observed in adipose tissue-derived MMSCs.

When cells were cultured in the adipogenic medium, we have observed the appearance of lipid inclusions stained with Oil Red 0 . The first lipid vacuoles in MMSCs cultures, regardless of the source, appeared in a day after the induction medium was added. In our studies, there was no difference in the number of cells containing lipid inclusion. Thus, in the bone marrow-derived MMSCs, the proportion of such cells was $92.0 \pm 1.0 \%$, in MMSCs from adipose tissue $-97.0 \pm 2.0 \%$ (Fig. 3 ).

The obtained data testify that differences were observed only for directed osteogenic differentiation of bone marrow-derived or adiposetissue-derived MMSCs.

\section{FEATURES OF IN VITRO IMIMUNOSUPPRESSIVE EFFECT OF BONE MARROW-DERIVED AND ADIPOSE TISSUE-DERIVED MIMSCS.}

One of the characteristic of MMSCs of various origin is immunomodulatory effect, which can be evaluated by inhibition of mitogenstimulated proliferation of lymphocytes in MTT assay. The analysis of literature data showed that mechanisms of both contact and non-contact interactions are involved in intercellular signaling between MMSCs and various subpopulations of immune cells. In case of co-culture with MMSCs a decrease of the proliferative activity of T-, B- and NK-cells, induction of anergy and apoptosis of T-cells, inhibition of mature dendritic cells, modulation of cytokine production by immune cells were detected [4446]. In our studies, it has been found that when activating splenocytes of adult intact mice with mitogen at the presence of bone marrow MMSCs, their proliferative potential decreases sharply (Fig. 4). In this case, the degree of proliferation inhibition of splenocytes by bone marrow-derived MMSCs depended on their number. With the increase in MMSCs dose of from $1.5 \cdot 10^{4}$ to $6.0 \cdot 10^{4}$, with prolonged cultivation with mitogen-stimulated splenocytes, the proliferative index decreased by $73 \%$ and $92 \%(p<0.05)$, respectively. The inhibition degree of splenocytes proliferation increased with an increase in the number of MMSCs, regardless of tissue origin. Thus, with the addition of $6.0 \cdot 10^{4}$ BM-MMSCs, there was a tendency for a decrease in proliferation index of splenocytes in 2.6 times compared with a dose of $3.0 \cdot 10^{4}$ MMSCs $(p>0.05)$. Such a pattern was revealed by the addition of AT-MMSCs but with a more pronounced inhibitory effect on the splenocytes proliferation: 7 times at a dose of $6.0 \cdot 10^{4}$ as compared with a dose of $3.0 \cdot 10^{4}(p<0.05)$. Consequently, the immunomodulatory effect of MMSCs on mitogen-induced proliferation of mouse splenocytes does not depend on the origin of the tissue.

MMSCs, regardless of tissue origin, can exhibit dose-dependent inhibitory effects on the proliferation of syngeneic splenocytes in mice with significant inhibition when co-cultured with a high dose of MMSCs. 


\section{CONCLUSION}

1. The murine bone marrow-derived and adipose tissue-derived stromal cell cultures express the typical markers for MMSCs on passage two. A distinctive feature of bone marrow-derived cells was the high level of expression of the hematopoietic markers CD45 and CD117.

2. MMSCs from both tissue sources are capable to differentiation into osteogenic and adipogenic directions. During osteogenic differentiation there was a change in the morphology of cells, they actively synthesized and mineralized the extracellular matrix, forming cellular aggregates. The semi-quantitative analysis of the mineralization degree of the extracellular matrix revealed that BM-MMSCs have a higher osteogenic potential compared with AT-MMSCs. MMSCs from both sources showed the characteristic features of adipogenic differentiation: the formation of lipid inclusions, which over time in the culture increased and fused.

3. MMSCs have an inhibitory effect on mitogen-induced proliferation of splenocytes in vitro. The intensity of such inhibition does not depend on the MMSCs origin. The dependence of the inhibition degree of splenocytes proliferation according to the ratio of MMSCs to splenocytes was revealed.

Bone marrow-derived and adipose tissue-derived MMSCs are candidates for application in regenerative medicine. Animal studies of biological properties of MMSCs from various tissues and mechanisms underlying their immunomodulatory effects expand the perceptions of the characteristics of MMSCs in order to optimize clinical application and development of new therapeutic approaches.

\section{REFERENCES}

1. Friedenstein AJ, Chailakhian RK, Lalykina KS. The development of fibroblast colonies in monolaier cultures of guinea pig bone marrow and spleen colonies. Cell Tissue Kinet. 1970; 3: 393-403.

2. Zuk PA, Zhu M, Mizuno H, et al. Multilineage cells from human adipose tissue: implications for cell-based therapies. Tissue Eng. 2001; 7: 211-226.

3. Fernandes KJ, Fernandes IA, McKenzie, et al. A dermal niche for multipotent adult skin-derived precursor cells. Nat Cell Biol. 2004; 6: 1082-1093.

4. Miao Z, Jin J, Chen L, et al. Isolation of mesenchymal stem cells from human placenta: comparison with human bone marrow mesenchymal stem cells. Cell Biol Int. 2006; 30: 681-687.

5. Kruglov PV, Lokhmatova EA, Klimovich VB, et al. Mezenkhimnye stvolovye kletki i immunopatologicheskie sostoyaniya organizma [Mesenchymal stem cells and immunopathological states of the body]. Kletochnaya transplantol i tkanevaya inzheneriya - Cellular Transplantation and Tissue Engineering. 2006; 3: 36-41. [In Russian]

6. Hass R, Kasper C, Bohm S, et al. Different populations and sources of human mesenchymal stem cells (MSC): A comparison of adult and neonatal tissue-derived MSC. Cells Comunication and Signalling. 2011; 9: 1-14.

7. Harvanová D, Tóthová T, Sarišský $M$, et al. Isolation and characterization of synovial mesenchymal stem cells. Folia Biol (Praha). 2011; 57(3): 119-124.

8. Ferretti C, Mattioli-Belmonte M. Periosteum derived stem cells for regenerative medicine proposals: Boosting current knowledge. World J Stem Cells. 2014; 6(3): 266-277.

9. Usas A, Huard J. Muscle-derived stem cells for tissue engineering and regenerative therapy. Biomaterials. 2007; 28(36): 5401-5406.

10. Park JR, Kim E, Janf J, et al. Isolation of human dermis derived mesenchymal stem cells using explants culture method: expansion and phenotypical characterization. Cell Tissue Bank. 2015; 16(2): 209-218.

11. Kuroda Y. Kitada M, Wakao S, et al. Bone marrow mesenchymal cells: how do they contribute to tissue repair and they really stem cells? Arch Immunol Ther Exp. 2011; 59: 369-378.

12. Orlic D, Kajstura J, Cimenti S. Bone marrow cells regenerate infarcted myocardium. Nature. 2011; 410: 701-705.

13. Sekiya I, Larson BL, Vuoristo JT, et al. Adipogenic differentiation of human adult stem cells from bone marrow stroma (MSCs). J Bone Miner Res. 2004; 2: 256-264.

14. Bommie F, Sung-No J. The Immunomodulatory Effects of Mesenchymal Stem Cells in Prevention or Treatment of Excessive Scars. Stem Cells International. 2016; Available: https:// dx.doi.org/10.1155/2016/6937976

15. Tyndall A, Uccelli A. Multipotent mesenchymal stromal cells for autoimmune diseases: teaching new dogs old tricks. Bone marrow transplantation. 2009; 43(11): 821-828.

16. Corcione A, Benvenuto F, Ferretti $E$, et al. Human mesenchymal stem cells modulate B-cell functions. Blood. 2006; 107(7): 3670-372.

17. Jiang $X X$, Zhang $Y$, Liu B, et al. Human mesenchymal stem cells inhibit differentiation and function of monocyte-derived dendritic cells. Blood. 2005; 105(10): 41204126.

18. Friedenstein AJ, Petrakova KV, Kurolesova Al, et al. Heterotopic of bone marrow. Analysis of precursor cells for osteogenic and hematopoietic tissues. Transplantation. 1968; 6: 230-247.

19. Rodbell M. Metabolism of isolated fat cells. I. Effects of hormones on glucose metabolism and lipolysis. J Biol Chem. 1964; 239: 375-380.

20. Cawthorn WP, Scheller EL, MacDougland OA. Adipose tissue stem cells meet preadipocyte commitment: going back to the future. J Lipid Res. 2012; 53: 227-246.

21. Tsuji W, Rubin JP, Marra KG. Adipose-derived stem cells: implications in tissue regeneration. World J Stem Cells. 2014; 6: 312-321.

22. Meirelles LDS, Chagastelles PC, Nardi NB. Mesenchymal stem cells reside in virtually all post-natal organs and tissues. Journal of Cell Science. 2006; 119(11): 22042213.

23. Kern S, Eichler H. Stoeve J, et al. Comparative analysis of mesenchymal stem cells from bone marrow, umbilical cord blood, or adipose tissue. Stem Cells. 2006; 24(5): 1294-1301.

24. Izadpanah R, Trygg C, Patel B, et al. Biologic properties of mesenchymal stem cells derived from bone marrow and adipose tissue. J Cell Biochem. 2006; 99: 1285-1297.

25. Mitchell JB, McIntosh K, Zvonic S, et al. Immunophenotype of human adipose-derived cells: temporal changes in stromalassociated and stem cell-associated markers. Stem Cells. 2006; 24: 376-385

26. Jeon BG, Kumar BM, Kang EJ, et al. Characterization and comparison of telomere length, telomerase and reverse transcriptase activity and gene expression in human mesenchymal stem cells and cancer cells of various origins. Cell Tissue Res. 2011; 345: 149-161. 
27. Sachs PC, Francis MP, Zhao M, et al. Defining essential stem cell characteristics in adipose-derived stromal cells extracted from distinct anatomical sites. Cell Tissue Res. 2012; 349: 505-515.

28. Lindroos B, Suuronen R, Miettinen S. The potential of adipose stem cells in regenerative medicine. Stem Cell Rev. 2011; 7:269-291.

29. Bear PC, Kuci $S$, Krause $M$, et al. Comprehensive phenotype characterization of human adipose-derived stromal/stem cells and their subsets by a high throughput technology. Stem Cells Dev. 2013; 22: 330-339.

30. Pittenger MF, Mackay AM, Beck SC, et al. Multilineage potential of adult human mesenchymal stem cells. Science. 1999; 284: 143-147.

31. Furno D, Mannino G, Cardile V, et al. Potential Therapeutic Applications of Adipose-Derived Mesenchymal Stem Cells. Stem Cells and Development. 2016; 25(21): 1615-1628. Available: https:// doi.org/10.1089/scd.2016.0135

32. Uzbas E, May ID, Parisi AM, et al. Molecular physiognomies and applications of adipose-derived stem cells. Stem Cell Rev Rep. $2015 ; 2$ : $298-308$.

33. Baptista LS, Silva KR, Borojevic R. Obesity and weight loss could alter the properties of adipose stem cells? World J Stem Cells. 2015; 7(1): 165-173.

34. Eticheskaya ekspertiza biomeditsinskikh issledovaniy [Prakticheskie rekomendatsii Ethical examination of biomedical research. Practical recommendations]. Ed. by YuB Belousov. Moskow: Rossiyskoe obshchestvo klinicheskikh issledovateley - Russian Society of Clinical Researchers, 2005. 156 p. [In Russian]

35. Prockop DJ, Phinney DG, Bunnell BA. Mesenchymal stem cells: methods and protocols. Totowa, NJ: Humana Press, $2008.192 \mathrm{p}$.

36. Dominici M, Le Blanc K, Mueller I. Minimal criteria for defining multipotent mesenchymal stromal cells. The International society for cellular therapy position statement. Cytotherapy. 2006; 8(4): 315-317.

37. Li J, Mareddy S, Tan DM, et al. A minimal common osteochondrocytic differentiation medium for the osteogenic and chondrogenic differentiation of bone marrow stromal cells in the construction of osteochondral graft. Tissue engineering Part A. 2009; 15(9): 2481-2490.

38. Gregory CA, Gunn WG, Peister A, et al. An alizarin red-based assay of mineralization by adherent cells in culture: comparison with cetylpyridinium chloride extraction. Analytical biochemistry. 2004; 329: 77-84.

39. Fernando AA, Dominique B. Isolation, culture, and differentiation potential of mouse marrow stromal cells. Curr Prot Stem Cell Biol. 2008; doi: 10.1002/9780470151808. $\mathrm{sc02b03s7}$

40. Mosman T. Rapid colorimetric assay for cellular growth and survival: application to proliferation and cytotoxicity assays. J Immunol Methods. 1983; 65(1): 55-63.

41. Lakin GF. Biometrics. Higher School, Moscow, 1990. 352 p.

42. Pino AM, Rosen JC, Pablo RJ. In osteoporosis, differentiation of mesenchymal stem cells (MSCs) improves bone marrow adipogenesis. Biol Res. 2012; $45: 279-287$.

43. Hong L, Colpan A, Peptan IA. Modulations of 17-beta estradiol on osteogenic and adipogenic differentiations of human mesenchymal stem cells. Tissue Eng. 2006; 12(10): 2747-2753.

44. Di NM, Carlo-Stella C, Magni M, et al. Human bone marrow stromal cells suppress T-lymphocyte proliferation induced by cellular or nonspecific mitogenic stimuli. Blood. 2002; 99(10): 3838-3843.

45. Le Blanc K, Tammik L, Sundberg D, et al. Mesenchymal stem cells inhibit and stimulate mixed lymphocyte cultures and mitogenic responses independently of the major histocompatibility complex. Scand J Immunol. 2003; 57(1):11-20.

46. Chamberlain G, Fox J, Ashton B, et al. Concise review: mesenchymal stem cells: their phenotype, differentiation capacity, immunological features, and potential for homing. Stem Cells. 2007; 25(11): 2739-2749.

\begin{tabular}{|l}
\hline \\
ARTICLE ON THE SITE \\
\hline
\end{tabular}

The author indicates no potential conflicts of interest.

Received: September 05, 2017

Accepted: November 30, 2017 